\title{
Experimental Investigation and Numerical Determination of Custom Gas Diffusion Layers on PEMFC Performance
}

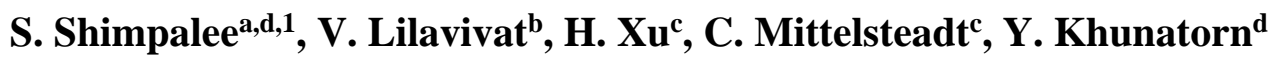 \\ ${ }^{a}$ Department of Chemical Engineering, \\ University of South Carolina, Columbia, SC 29208 \\ ${ }^{\mathrm{b}}$ National Metal and Materials Technology Center (MTEC) \\ 114 Thailand Science Park, Pathum Thani 12120, Thailand \\ ${ }^{\mathrm{c}}$ Giner Electrochemical Systems, LLC \\ 89 Rumford Ave. Newton, MA 02466 \\ ${ }^{\mathrm{d}}$ Department of Mechanical Engineering \\ Faculty of Engineering, Chiang Mai University \\ Chiang Mai, 50200, Thailand
}

Submitted to

Electrochemica Acta

Submitted to as Research Article

1- Corresponding author: Phone: (803) 576-6140; FAX: (803) 777-8142, e-mail: shimpale@cec.sc.edu 


\begin{abstract}
The objective of this work is to investigate the design of gas diffusion layer (GDL) for fuel cells that possess specific transport properties. Various types of custom GDLs that have a microporous bilayer (MP) were studied. These GDLs have two different MP layers and a carbon substrate. GDLs with different bilayer MPs designs were tested and the fuel cells performance was investigated. The performance of the fuel cell was measured in-situ with different GDLs at several operating conditions. The pore morphology of the GDLs as well as pore size distribution of the GDLs including the MPs was determined. The data on the pore size distribution including the relationship between tortuosity and porosity was used as model parameters. The experimental data and model predictions confirm that introducing the bilayer MPs on the substrate could improve the transport resistant and increase the performance of PEMFC. The effect of carbon particle size and overall diffusivity also modified the value of MacMullin number and overall thickness of GDL causing the differences in performance and local distributions.
\end{abstract}

Keywords: Proton Exchange Membrane Fuel Cell (PEMFC); Gas Diffusion Layer; Micro Porous Layer; Pore Size Distribution; Current Density Distribution. 


\section{Introduction}

Water heavily influences the proton exchange membrane fuel cells (PEMFC) performance, in particular for fuel cells operating at high humidity and current conditions. This makes determining proper water management very important which requires a good understanding of water transport in the different components of the cell, such as the gas diffusion layer (GDL). The GDL is a vital components to PEMFCs since it has a variety of functions significant to their overall performance and water management [2]. The GDL is usually a dual-layer carbon based porous substrate and is typically treated with polytetrafluoroethylene (PTFE) to make it hydrophobic in order to avoid liquid water blockage of its internal pores so as to keep them available for reactant gas transport to the adjacent catalyst layer [3]. It was discovered that the liquid water distribution was strongly dependent on the hydrophilicity of the GDL [4]. When the gas phase is saturated with water vapor, water condensation takes place and the resulting liquid water starts to fill the open pores of the GDL and cover the catalyst particles, rendering them electrochemically inactive [5]. The maximum current density is limited by oxygen concentration at the cathode catalyst surface [6]. This maximum value represents the oxygen transport limitation through the GDL. The mass transfer through the GDL may be the rate limiting factor at high current densities when the GDL is saturated with water [7]. Nam and Kaviany [8] suggested that water transports through the GDL via capillary motion in a large main stream that is extended from the catalyst layer to the gas channel. The micro porous layer (MP) was introduced to enhance the water management and electrical contacts [9]. Different pore sizes, materials and structures of MP affect the PEMFC performance [10]. 
In this study GDLs of different designs were created by the introduction of two MPs and their effect on the PEMFC performance was investigated through the characterization of their materials and structures. Morgan and Datta [11] suggested that the multiple MPLs on a GDL could provide not only a higher limiting current density, but also improve the performance throughout by reducing the overpotential and interfacial contacts due to enhance water transport properties. Therefore, the design of the new GDL was made from modifying a standard AvCarb ${ }^{\circledR}$ GDL by adding two micro porous layers. Each set was treated by two different methods in order to provide two different values of diffusivity. Moreover, two micro porous layers have been constructed with two different sizes of carbon particles. It is well known that tortuosity $(\tau)$ and porosity $(\varepsilon)$ are two important parameters relating free-stream properties with the actual mass transport in GDLs [12].

In addition to these experiments, we included a computational fluid dynamic (CFD) analysis to enhance the understanding of the experimental data. This model will integrate the GDL properties including MacMullin number and pore size distribution (PSD). The CFD prediction of current density distribution and gas/water transports in PEMFC will describe the local transports affected by the new designs of the GDL.

\section{Experimental Procedure}

Three different standard carbon substrates from $\mathrm{AvCarb}^{\circledR}$ (former Ballard Material Products: EP40, P50 and P75) were selected for this study. The custom GDLs were modified from the standard AvCarb ${ }^{\circledR}$ carbon substrate by adding two MPs as shown in Figure 1. For the substrate, the diffusivity can be controlled by modifying the fill matrix in the substrate or by changing key parameters in the manufacturing process to alter the pore structure. The critical process parameters come from the five process steps used to produce the substrate (i.e., Ink mixing, coating, 3 roll-toroll heat treatments). The PTFE content in the substrate was added to control the hydrophobicity 
level, which also directly impacts both the total porosity and the effective water vapor diffusivity of the GDL. Therefore, the two different values of diffusivity of each substrate (i.e., $<0.15 \mathrm{~cm}^{2} / \mathrm{s}$ and $>0.35 \mathrm{~cm}^{2} / \mathrm{s}$ ) were chosen in this work. Two MPs were also created by employing two different sizes of carbon particle (i.e., small and large). Both MPs were made by carbon powder under different characteristics. For the large particle, the fine black power from Imerys Graphite \& Carbon was used with the crystallite height around $100 \mathrm{~nm}$. For the small particle, the carbon black was introduced with the crystallite height around $30 \mathrm{~nm}$. These two MPLs were designed to have the total thickness around 40-50 $\mu \mathrm{m}$. The PTFE content between 5\% and 10\% was also added into the MPs. Table 1 shows a list of the twelve samples of custom GDLs used for this experiment and they were compared with standard GDLs.

The GDLs were evaluated by in-situ experimental setup on a 50- $\mathrm{cm}^{2}$ PEMFC single cell hardware. The custom GDLs were assembled into the fuel cell with MP1 located between substrate and MP2. The MP2 was attached to the membrane electrode assembly (MEA). The GORETM 57 series MEA were used for all experiments. Due to the different thickness of GDL samples, the compression pressure during fuel cell assembly was maintained as close as possible to $550 \mathrm{kPa}$. The inlet relative humidity in the gas stream of both anode and cathode were set at three different relative humidity $(\mathrm{RH})$ conditions $(25 \% / 25 \%, 75 \% / 25 \%$ and $100 \% / 50 \%)$. For $100 / 50 \% \mathrm{RH}$ condition, the system pressure of fuel cell was set to $136 \mathrm{kPa}$ for both anode and cathode. The polarization curves from different GDLs were measured from $0.3 \mathrm{~V}$ to open circuit voltage. The high frequency resistance (HFR) at $1000 \mathrm{~Hz}$ was also measured during the experiment for GDL resistance. The detailed operating conditions are given in Table 2 .

For ex-situ study of the GDL, an electrical resistance measurement was used to determine the MacMullin number of the different GDL samples. The value of the MacMullin number 
describes the porous structures as the ratio between tortuosity and porosity. These two important parameters are related to the free-stream properties and the actual mass transport in porous material [12]. The relationship of the MacMullin number to the tortuosity and porosity depends on its structure including the micro porous layer if available and the total thickness. The electrical resistance is often used in studies of flow through porous media and reported as the MacMullin number. This number, based on the work of MacMullin and Muccini [13] is defined as

$$
\text { MacMullin number }=\frac{R}{R_{0}}
$$

where $R$ is resistance of the porous media saturated with an electrolyte and $R o$ is the bulk resistance of the same electrolyte. The same technique as Martínez et al. [12] was used to measure the value of MacMullin number. The MacMullin number of all the GDL samples was also reported in Table 1. Further, the thickness of all samples was also given in Table 1 and they were changed at different substrates (i.e., EP40, P50, and P75) due to the different in composition, structure, and manufacturing treatment. It is noted that the performance may be contributed by the thickness of GDL that controls the diffusion path lengths, water flooding, thermal and electrical resistance. However, in this work, the effect of the thickness was minimized by maintaining the compression pressure inside the PEMFC at around $550 \mathrm{kPa}$ for all samples as already mentioned. Moreover, the effect of GDL thickness was also included as the ratio between tortuosity and porosity in the form of MacMullin number. It was reported as also mentioned above.

\section{Model development}

A computational continuum mechanics (CCM) technique based on a commercial flow solver, STAR-CD 4.18, was used to solve the coupled governing equations [14]. This software has an add-on module called expert system of proton exchange membrane fuel cell (ES-PEMFC) 
version 2.51 that incorporates multi-physics of PEMFC [14]. These require the source terms for species transport, multiphase flow, and heat generation equations [14-17]. Also, es-pemfc accounted for the flux of protons and water across the membrane [15]. The material properties, parameters, and operating conditions used for this work are shown in Tables 2 to 4 . The cell temperature and the system pressure given in Table 3 are the initial values or they can be called as the operating temperature and the operating system pressure, respectively. Note that the gas utilization of both anode and cathode are maintained constant as required by a particular operating condition. This model has been validated with experimental data and the results were satisfied in polarization data [18], water balance data [19], and local current mapping data [20]. Note that the Ref. 20 also showed the model validation with one of GDL samples used in this study (i.e., EP40T).

The model geometry of PEMFC used in the simulation was exactly the same as what was used in the experiment. It has an active area of $50 \mathrm{~cm}^{2}$. This model geometry consists of an anode bipolar plate with triple-serpentine flow channel, gasket, anode GDL, MEA, cathode GDL, gasket, and a cathode bipolar plate with quadruple-serpentine flow channel. Co-current flow direction was chosen in this study same as in the experiment. The detailed dimension of geometry used in this simulation are also given in Table 3. The operating conditions input into the model were consistent with experimental conditions as given in Table 2. The number of computational cells used in the model is about one million cells. In addition, the detailed porous structure in the form of PSD, shown in Figure 3 were translated into local porosity versus distance in thickness direction of GDL/MPs (i.e., z-direction). This local porosity profiles were input into user defined subroutines to calculate for local permeability, diffusivity, and thermal conductivity [20-22]. This enhanced realistic calculation of transport inside the gas diffusion layer. 


\section{Results and Discussion}

Figure 4 shows the high-resolution scanning electron microscopy (SEM) images of the GDL/MPs samples. The EP40 and P75 substrates were selected as shown in Figs 4a and 4b, respectively. Each set of figure consists of surfaces of substrate and MPs and cross-sectional views of GDL/MP1/MP2 and standard GDL. For the structure of the substrate surface, both EP40 and P75 look similar to the carbon fiber patterns for both high and low diffusivity treatments. However, the P75 substrate seems to have larger amounts of wet proofing agents (i.e., PTFE) than EP40 substrate. For the micro porous surface applied in both EP40 and P75, obviously the smaller carbon particle size MP has a smoother surface than the larger carbon particle size MP. Figure 4 also shows cross-sectional views of the structure of the GDLs and MPs. These figures clearly show the difference between standard GDL without MPs and the new design of GDL with double MPs for EP40 and P75 samples. However, it is difficult to distinguish the significant differences between large and small carbon particles of MPs from the cross-sectional views. This could be due to the obstruction from wet proofing and binding proxies blocking the structural view. The thickness range of the substrate was estimated at 180-190 $\mu \mathrm{m}$ for EP40 and $220-230 \mu \mathrm{m}$ for P75. When the MPs were added on top of EP40 substrate, the thickness increased to 220-230 $\mu \mathrm{m}$ for high diffusivity and 240-250 $\mu \mathrm{m}$ for low diffusivity. For P75 substrate with MPs, the thickness increased to 250-260 $\mu \mathrm{m}$ for high diffusivity and 280-290 $\mu \mathrm{m}$ for low diffusivity.

Figures 5 to 7 show the effect of humidity conditions on the performance of PEMFC for three main substrates, EP40, P75, and P50, respectively. The two MPs included on these substrates have different size of carbon particles. Therefore, each graph contains five plots that are substrate only, high diffusivity with large carbon particle MP1 and small carbon particle MP2, low diffusivity with large carbon particle MP1 and small carbon particle MP2, high diffusivity with 
small carbon particle MP1 and large carbon particle MP2, and low diffusivity with small carbon particle MP1 and large carbon particle MP2. These sets of conditions are also shown in Table 1.

From Figure 5, it shows that the high diffusivity of the EP40 substrate with large carbon particle size in MP1 and small carbon particle size in MP2 gave the highest performance and was less sensitive to the humidity inside the cell as its performance only slightly increased with increasing gas inlet humidity. However under the same substrate but with small carbon particle size in MP1 and large carbon particle size in MP2, its performance rose when the humidity was increased. For the standard EP40T without any MP, it showed the lowest performance at the dry operating condition. However, its performance improved significantly under wet condition. This could be due to the hydrophobic treatment in the substrate EP40. For the case of low diffusivity EP40 substrate, the overall performance of each humidity condition was independent on the carbon particle size in micro porous layers as they both show similar results. Further, they showed the lowest performance compared to other designs at the high humidity condition (i.e., 100/50 \% RH with $136 \mathrm{kPa}$ ). It is also noted that in these sets of GDLs/MPs samples, the liquid water flooding in the PEMFC was minimal. Therefore, the ability of the gas diffusivity especially oxygen is improved which is the reason for the performance differences as it is a major factor in performance.

Figure 6 shows the same graphs as Fig. 5 but the substrate is changed to P75. The experimental data show that the low diffusivity substrate with small carbon particle MP1 and large carbon particle MP2 shows the lowest performance for all conditions. This is because the high tortuosity which corresponds to a high value for the MacMullin number. The higher MacMullin number will impact the water transport inside the GDL/MP creating the high possibility of water flooding especially at higher humidity as shown in this figure. This water flooding phenomena can increase the resistance of the reacting gases in particular for oxygen to diffuse to the catalyst 
surface thus increasing the over-potential. Similar to Figure 5, the high diffusivity substrate with large carbon particle MP1 and small carbon particle MP2 gives high performance and shows less sensitive to the humidity. However with the low diffusivity substrate, the performance shows great sensitive to the humidity as its performance increases with increasing humidity to reach the highest performance over other GDL/MPs. For substrate only, it reveals that P75T gives comparable performance especially when the humidity is high and it has higher performance than EP40T shown in Figure 5.

Figure 7 shows the cases for P50 substrate with different sets of MP1 and MP2. It is important to show that the carbon particle size of MP significantly impacts the performance under the low diffusivity substrate. The large carbon particle MP1 and small carbon particle MP2 shows the highest performance for all humidity conditions whereas the small carbon particle MP1 and large carbon particle MP2 gives the lowest performance for all humidity conditions. In other words, the large carbon particle MP1 and small carbon particle MP2 has better control of water saturation and oxygen transport than small carbon particle MP1 and large carbon particle MP2. For the high diffusivity substrate, the effect of carbon particle size on the performance is minimal and their performance is slightly higher than the fuel cell with substrate only. Once again, their performance is increasing when the humidity is increased. The detailed analysis is given in Figures 8 to 10 .

Figure 8 presents the performance comparison of the three main substrates (P50, P75, and EP40) with large carbon particles in MP1 and small carbon particles in MP2. The line plots present overall performance at humidity condition of $75 / 25 \% \mathrm{RH}$ and the bar graphs provide the current density comparison at three different inlet humidity conditions at a cell potential of $0.6 \mathrm{~V}$. When the substrate has high diffusivity as shown in Fig. 8a, the EP40 substrate gave the highest 
performance whereas P75 and P50 show similar performance. Again, the performance is improved when the humidity inside the cell is increased. The P50 substrate favors the high humidity more than the other substrates especially when compared with P75. When the substrate is changed to low diffusivity (Fig. 8b), P50 shows similar performance as when its diffusivity is high. But for both EP40 and P50 substrates, their performance is decreased.

When the carbon particle size of MP1 and MP2 is changed from large to small for MP1 and small to large for MP2, the experimental results and model predictions are shown in Fig. 9. For large diffusivity on substrate (Fig. 9a), all samples give similar performance even though EP40 shows slightly higher performance than others for lower humidity conditions. For high operating conditions (e.g., 100/50 \% RH $136 \mathrm{kPa}$ ), P75 substrate gives the highest performance and EP40 provides the lowest performance. Once the diffusivity of substrate is reduced as shown in Fig $9 \mathrm{~b}$, the performance of P75 is significantly dropped to the lowest and this set of GDL/MPLs does not appreciate the increasing in humidity inside the PEMFC. The EP40 substrate shows the highest performance and it is much higher once the inlet humidity is increased to $100 / 50 \% \mathrm{RH}$ with 136 $\mathrm{kPa}$. For P50 substrate, its performance seems stable and less sensitive to the operating condition when compared with high diffusivity substrate.

The current density distribution and membrane water content of custom GDLs via CFD simulation are depicted in Figure 10. The simulation is under High diffusivity, MP1-Large, and MP2-Small at Iavg of $1 \mathrm{~A} / \mathrm{cm}^{2}$. From this figure, P75 has the most non-uniform distribution and EP40 shows the most uniform distribution with high value of membrane water content. When the diffusivity of substrate is Low as shown in Figure 11, P75 also shows the most non-uniform in distribution whereas EP40 gives the highest average value of membrane water content and it also gives the most uniform distributions. From these two figures, when the diffusivity of substrate is 
reduced, the performance gets lower and the uniformity of distributions become worse. In summary, EP40 GDL has the stable high performance for all conditions with any treatment shown above. The overall performance using P50 GDL is more independence on carbon particle on MP1 and MP2 and treatment for diffusivity when compared with EP40 and P75 GDLs. Furthermore, GDL P50 gives the higher performance. P75 GDL gives the lowest performance.

\section{Conclusions}

Bilayer micro porous layers have been successfully created and tested under various operating conditions. High diffusivity substrate can enhance transport resistance thus increasing the performance. The EP40 GDL has stable high performance for all conditions with any treatment. However impact of carbon particle size of MPs in P50 GDL on the PEMFC performance is minimal when it is compared with EP40 and P75 GDLs. Furthermore, the performance under custom P50 GDL has less effect on diffusivity of substrate under large carbon particle size MP1 and small carbon particle size MP2. For small carbon particle size MP1 and large carbon particle size MP2, P75 GDL shows the worst performance under low diffusivity substrate but its performance increases significantly when the diffusivity of substrate is increased.

For the overall performance, P75 GDL gives the lowest performance and also shows the most non-uniform distributions whereas, EP40 GDL shows the most uniform distribution with high values of water content. Using the data of pore size distribution information and MacMullin Number from GDL characterization, CFD predictions could be compared to experimental data. .

\section{Acknowledgements}

The authors would like to acknowledge Giner, Inc., Tech-Etch, Inc., CD-adapco, Altair Engineering, Inc, and the University Spectroscopy and Imaging Facilities at University of Arizona. 
Special thanks to Dr. Jason Morgan from AvCarb Material Solutions to provide all GDL/MPs samples. They also would like to thank the Department of Energy (grant \# DE-EE0000471) for their financial supports. The authors appreciate Mr. Cody Wilkins for his help reviewing this paper. Lastly, the authors also would like to acknowledge the collaboration agreement between University of South Carolina and Chiang Mai University.

\section{References}

1. L. R. Jordan, A. K. Shukla, T. Behrsing, N. R. Avery, B. C. Muddle and M. Forsyth, Journal of Power Sources, 86, 250 (2000).

2. J. Chen, T. Matsuura and M. Hori, Journal of Power Sources, 131, 155 (2004).

3. M. V. Williams, E. Begg, L. Bonville, H. R. Kunz and J. M. Fenton, Journal of The Electrochemical Society, 151, A1173 (2004).

4. H. Park, Energy Conversion and Management, 81, 220 (2014).

5. U. Pasaogullari and C. Y. Wang, Journal of The Electrochemical Society, 151, A399 (2004).

6. A. A. Kulikovsky, Electrochemistry Communications, 4, 939 (2002).

7. J. T. Gostick, M. A. Ioannidis, M. W. Fowler and M. D. Pritzker, Journal of Power Sources, 173, 277 (2007).

8. J. H. Nam and M. Kaviany, International Journal of Heat and Mass Transfer, 46, 4595 (2003).

9. A. Z. Weber and J. Newman, Journal of The Electrochemical Society, 152, A677 (2005).

10. J. Cho, H. Oh, J. Park, K. Min, E. Lee and J.-Y. Jyoung, International Journal of Hydrogen Energy, 39, 459 (2014).

11. J. Morgan and R. Datta, Journal of Power Sources, 251, 269-278 (2014). 
12. M. J. Martínez, S. Shimpalee and J. W. Van Zee, Journal of The Electrochemical Society, 156, B80 (2009).

13. R. B. MacMullin and G. A. Muccini, AIChE Journal, 2, 393 (1956).

14. Star-CD 4.18 Methodology, CD adapco Group, http://www.adapco.com.

15. ES-PEMFC Methodology and Tutorial Manual, CD adapco Group, http://www.adapco.com.

16. D.H. Jeon, S. Greenway, S. Shimpalee, J.W. Van Zee, Int J Hydrogen Energ, 33 (2008) 1052-1066.

17. S. Shimpalee, V. Lilavivat, J.W. Van Zee, H. McCrabb, A. Lozano-Morales, Int J Hydrogen Energ, 36 (2011) 12512-12523

18. W.K. Lee, S. Shimpalee, J.W. Van Zee, J Electrochem Soc, 150 (2003) A341-A348

19. S. Shimpalee, M. Ohashi, J.W. Van Zee, C. Ziegler, C. Stoeckmann, C. Sadeler, C. Hebling, Electrochimica Acta, 54 (2009) 2899-2911.

20. V. Lilavivat, S. Shimpalee, J. W. Van Zee, H. Xu, C.K. Mittlesteadt, Electrochimica Acta, 174 (2015), 1253-1260.

21. S. Shimpalee, M. Martinez, and J. W. Van Zee, Abstract \# 460, 210 Meeting of The Electrochemical Society, October 29 - November 03, 2006, Cancun, Mexico.

22. V. Lilavivat, S. Shimpalee, H. Xu, and C. Mittlesteadt, Abstract \# 1222, 226th Meeting of The Electrochemical Society, October 5, 2014, Cancun, Mexico. 


\section{List of Figures}

Figure 1: Design of custom gas diffusion media from AvCarb with two micro layers.

Figure 2: The SEM images at cross section of custom GDLs showing the location and structure of MP1 and MP2.

Figure 3: Comparison of Mercury pore size distributions of new design.

Figure 4: Structure of GDLs: a) EP40 and b) P75

Figure 5: The effect of customization for EP40 GDL on PEMFC performance under different operating conditions.

Figure 6: The effect of customization for P75 GDL on PEMFC performance under different operating conditions.

Figure 7: The effect of customization for P50 GDL on PEMFC performance under different operating conditions.

Figure 8: The effect of diffusivity of carbon substrate with MP1: Large, MP2: Small on PEMFC performance under $75 \% / 25 \% \mathrm{RH}$ operating condition.

Figure 9: The effect of diffusivity of carbon substrate with MP1: Small, MP2: Large on PEMFC performance under $75 \% / 25 \% \mathrm{RH}$ operating condition.

Figure 10: Local distributions at $\mathrm{I}_{\mathrm{avg}}$ of $1.0 \mathrm{~A} / \mathrm{cm}^{2}$ under $75 \% / 25 \% \mathrm{RH}$ operating condition. The diffusivity of carbon substrate is High with MP1: Large, MP2: Small.

Figure 11: Local distributions at $\mathrm{I}_{\text {avg }}$ of $1.0 \mathrm{~A} / \mathrm{cm}^{2}$ under $75 \% / 25 \% \mathrm{RH}$ operating condition. The diffusivity of carbon substrate is Low with MP1: Large, MP2: Small. 


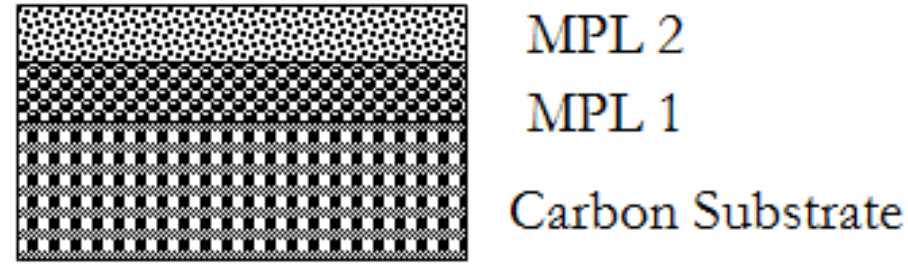

\begin{tabular}{|c|c|c|}
\hline Substrate & $\begin{array}{c}\text { Diffusivity } \\
\text { Modification }\end{array}$ & $\begin{array}{c}\text { MPL 1/MPL2 } \\
\text { (carbon particle size) }\end{array}$ \\
\hline P50 & Low & Small/Large \\
EP40 & High & Large/Small \\
\hline
\end{tabular}

Figure 1: 

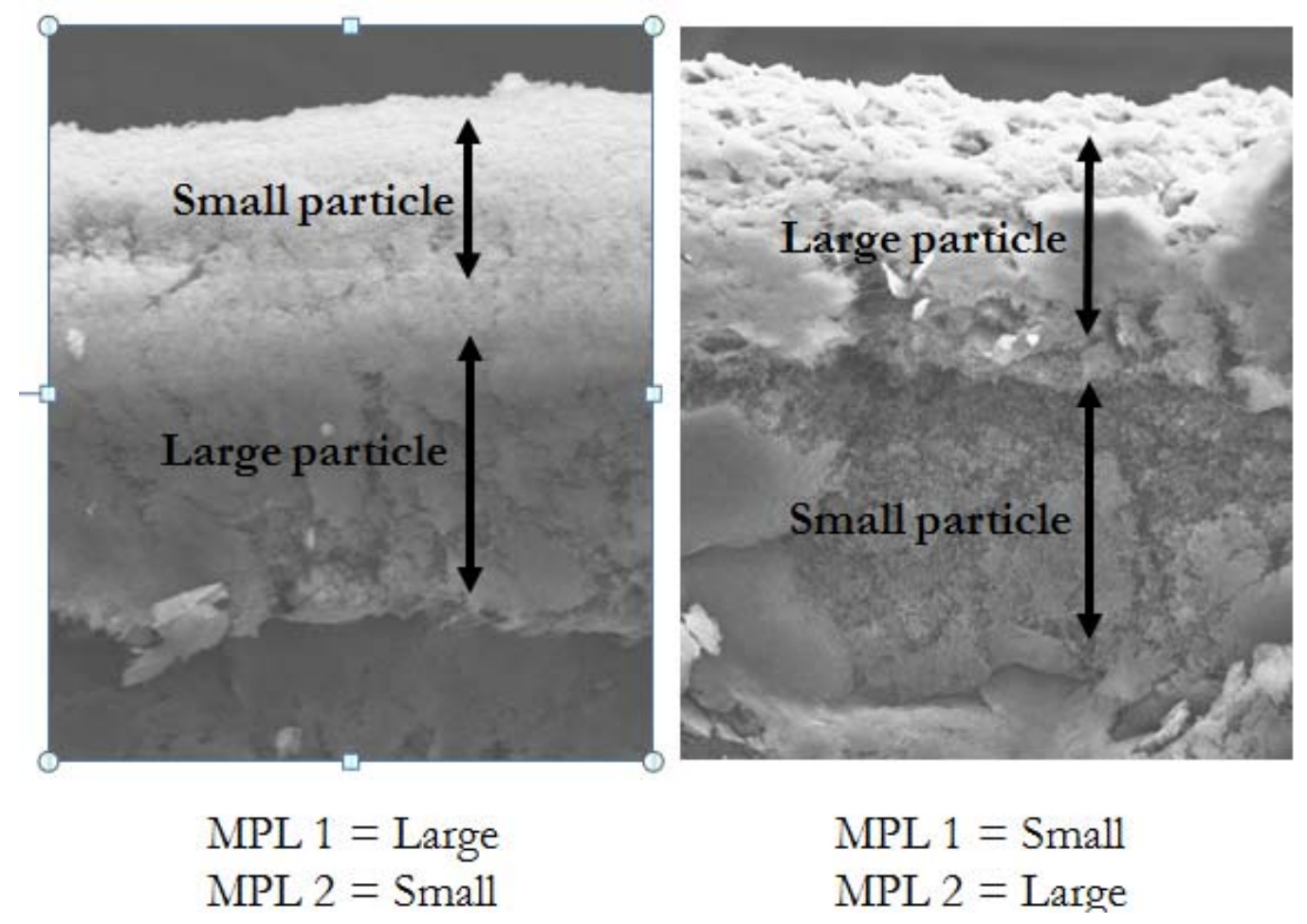

Figure 2: 
Baseline Substrates

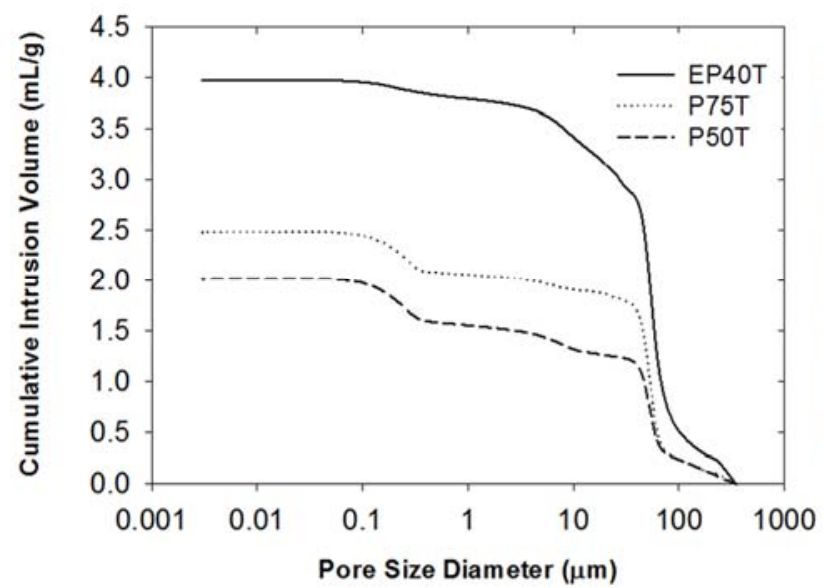

Modified Substrates

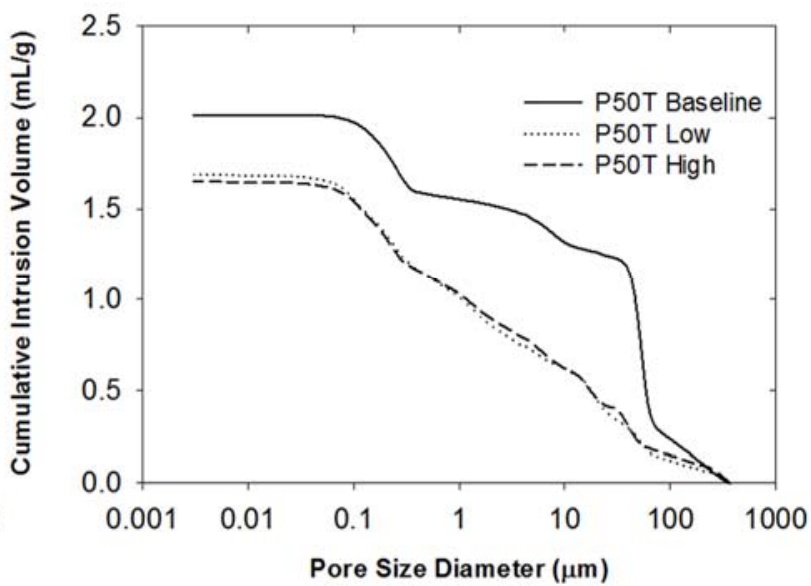

Cumulative Pore Volume
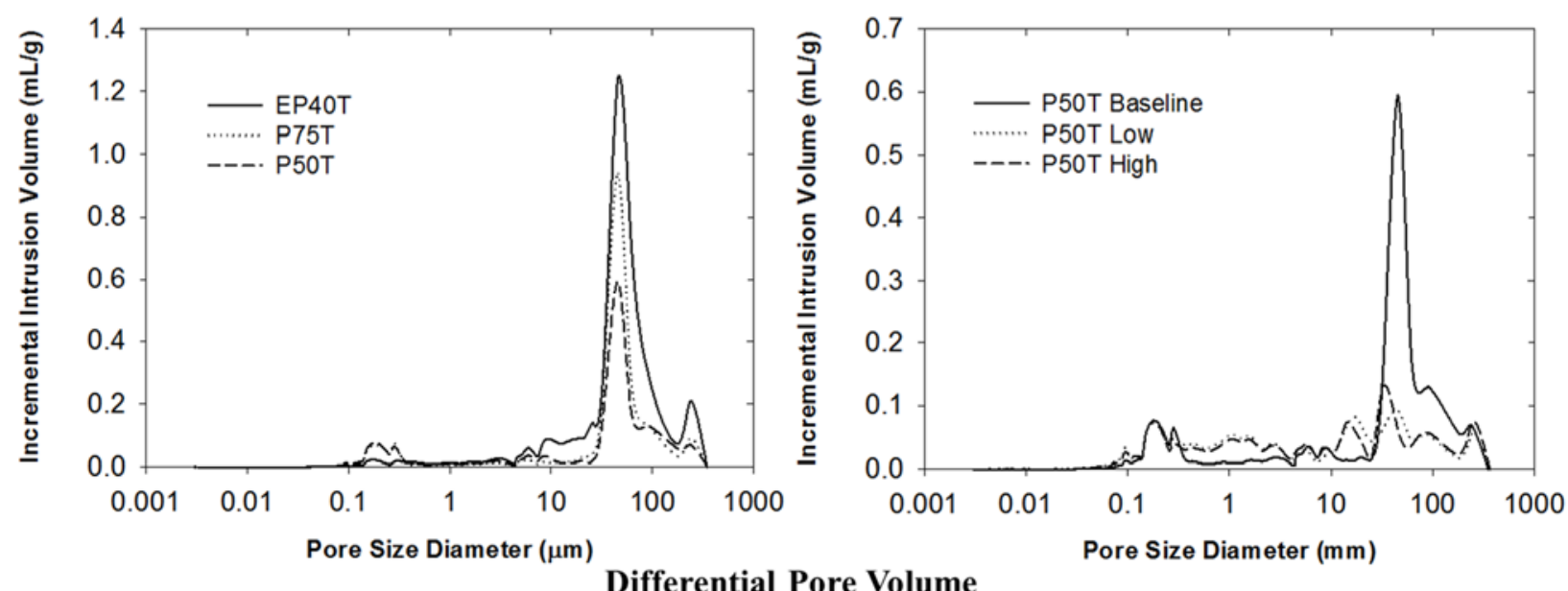

Figure 3: 
High-diffusivity substrate surface

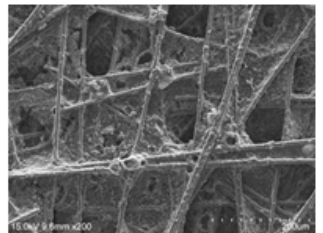

Small particle surface

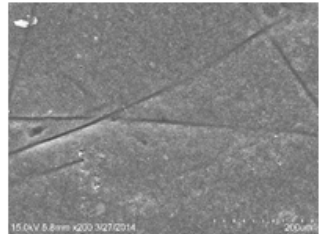

Large particle surface

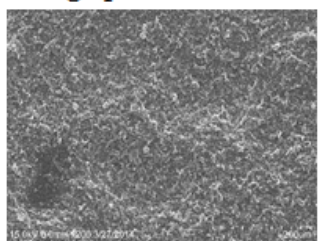

Low-diffusivity substrate surface

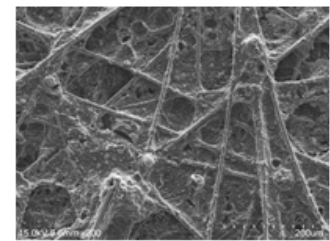

EP40 High - Large/Small

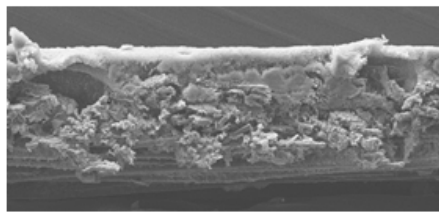

EP40 Low - Large/Small

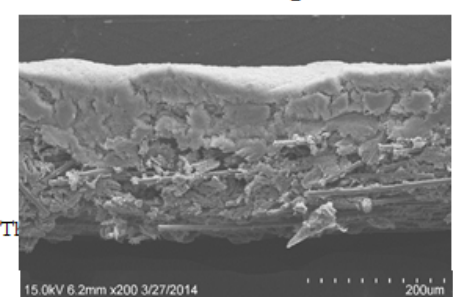

(a)

High-diffusivity substrate surface

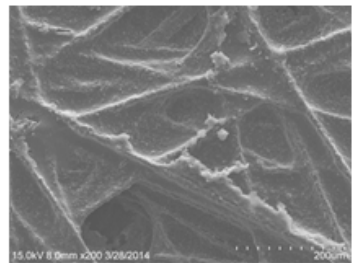

Small particle surface

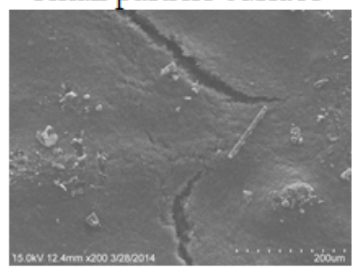

Large particle surface

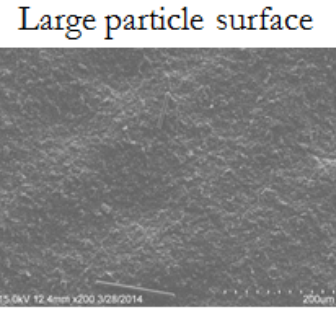

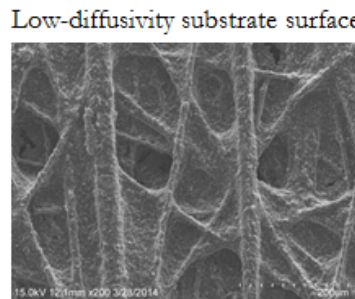

P75 High - Large/Small

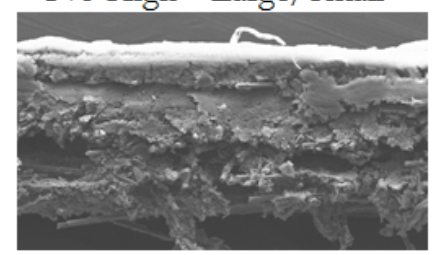

P75 Low - Large/Small

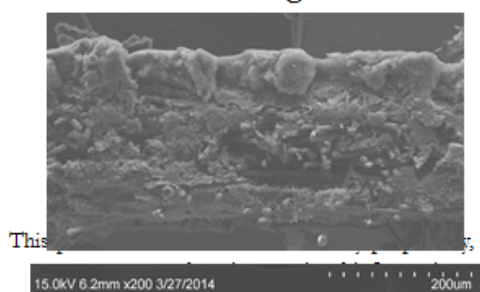

(b)
EP40T - standard

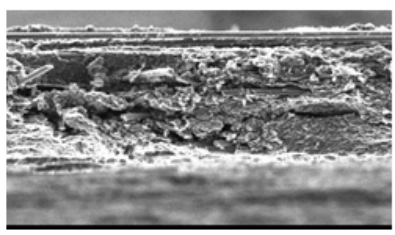

EP40 High - Small/large

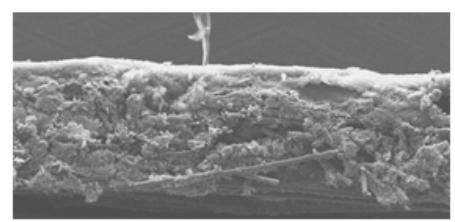

EP40 Low - Small/large

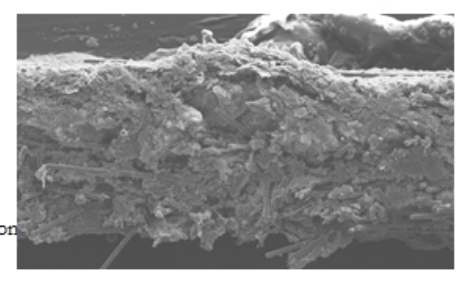

P75T - standard

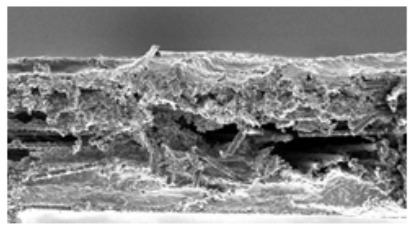

P75 High - Small/large

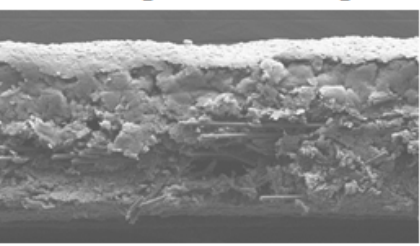

P75 Low - Small/large

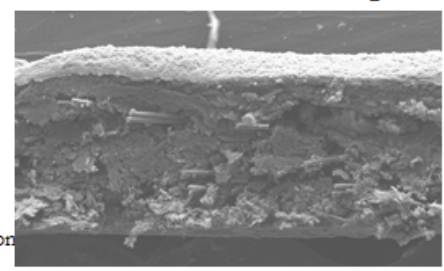

Figure 4: 


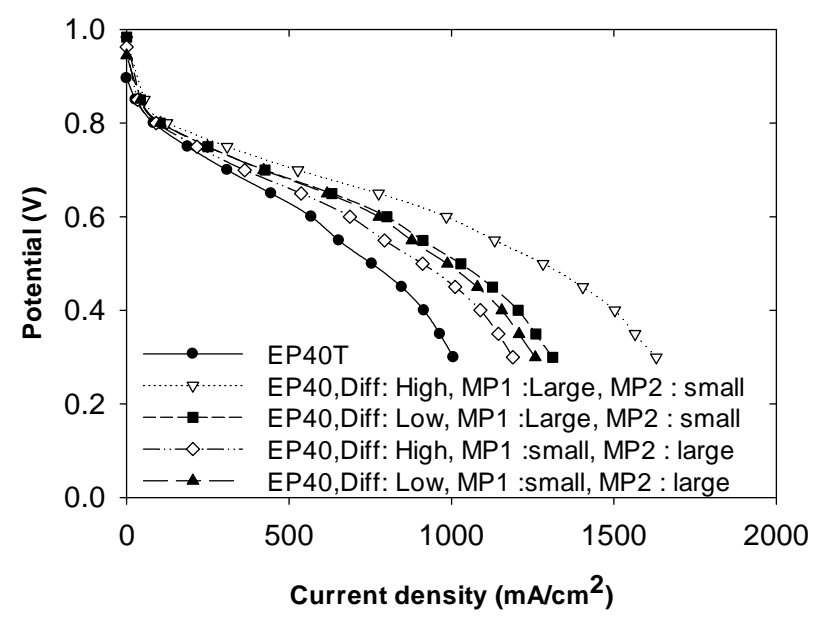

(a) $25 \% / 25 \% \mathrm{RH}$

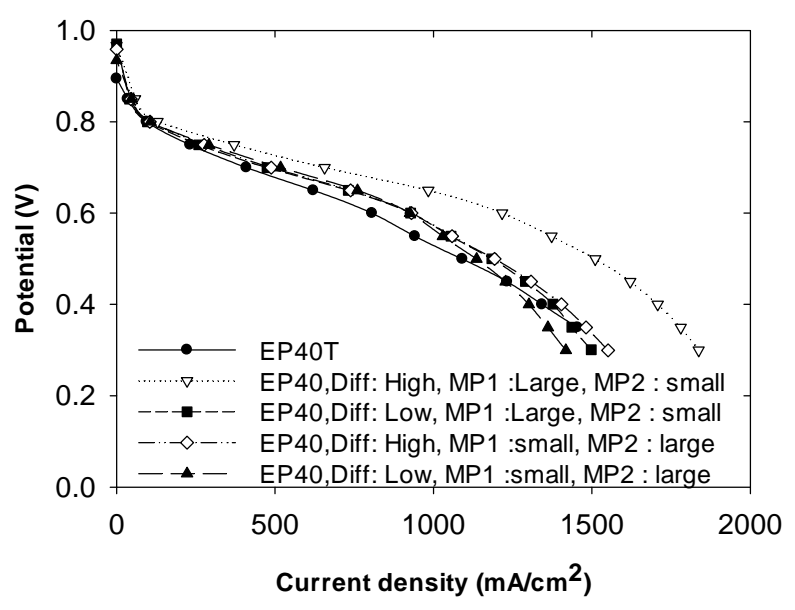

(b) $75 \% / 25 \% \mathrm{RH}$

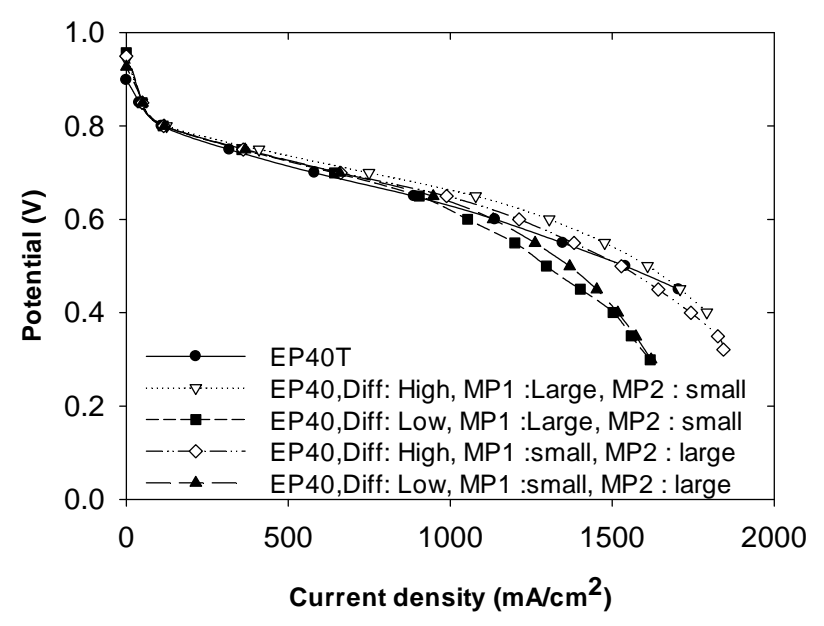

(c) $100 \% / 50 \% \mathrm{RH}$ with $136 \mathrm{kPa}$

Figure 5: 


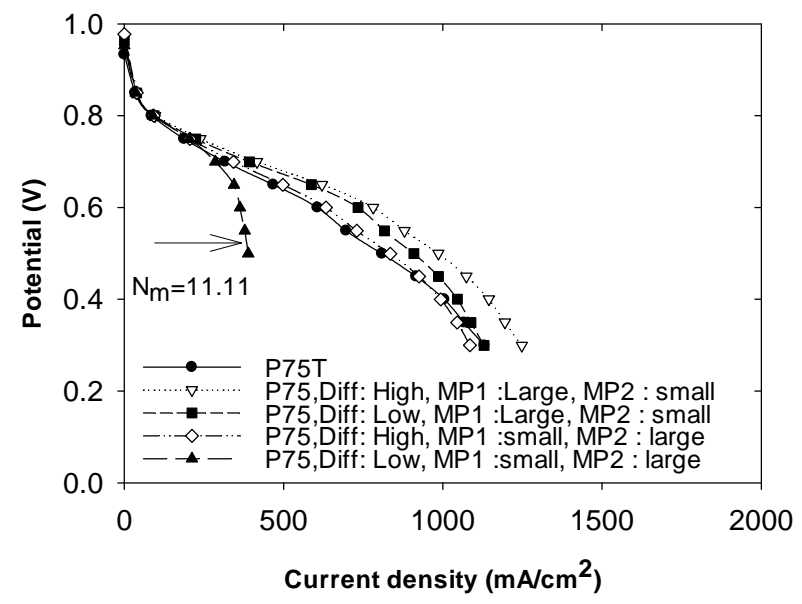

(a) $25 \% / 25 \% \mathrm{RH}$

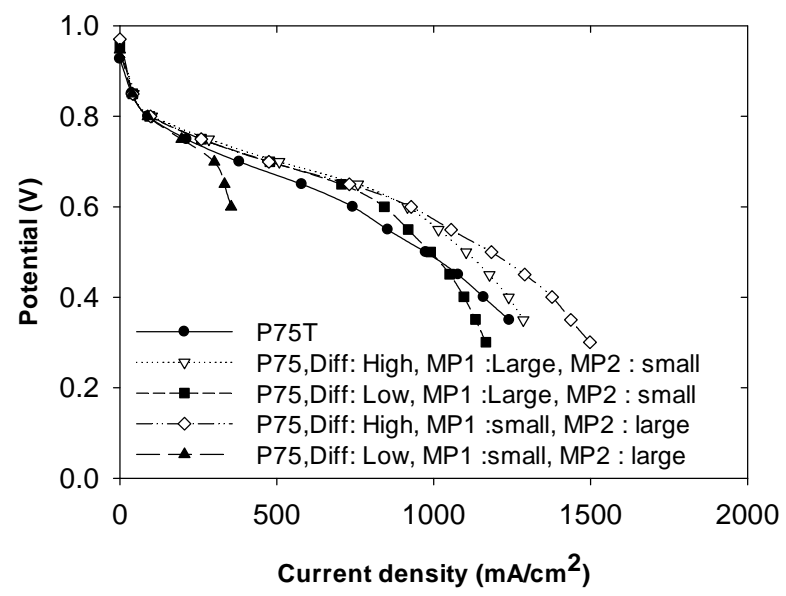

(b) $75 \% / 25 \% \mathrm{RH}$

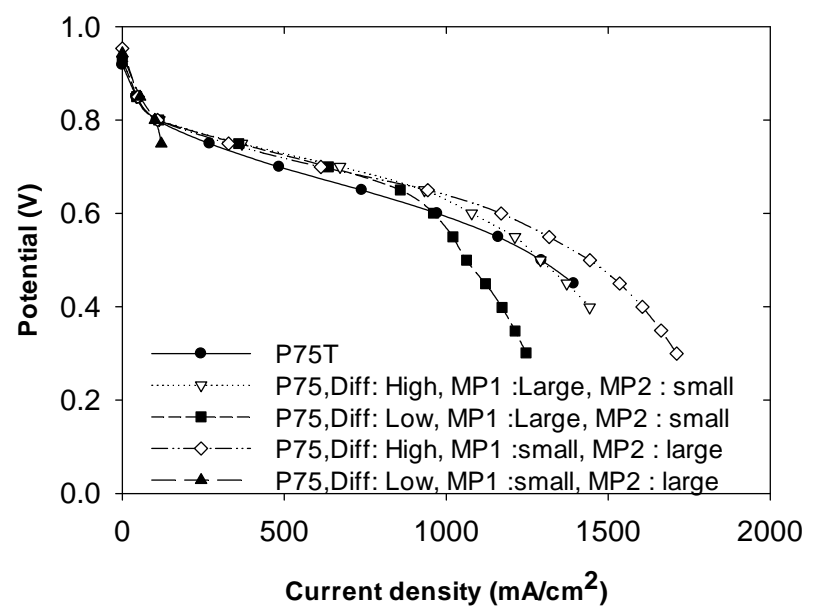

(c) $100 \% / 50 \%$ with $136 \mathrm{kPa}$

Figure 6: 


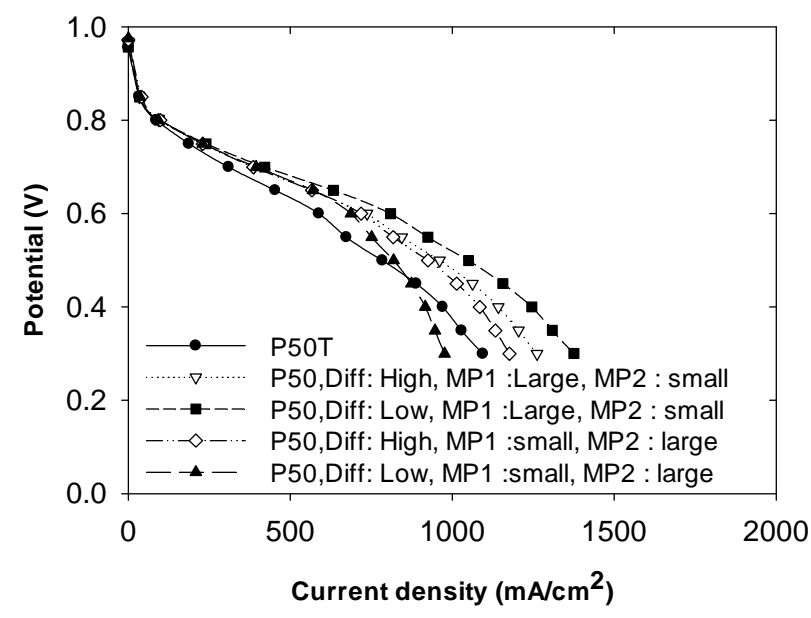

(a) $25 \% / 25 \% \mathrm{RH}$

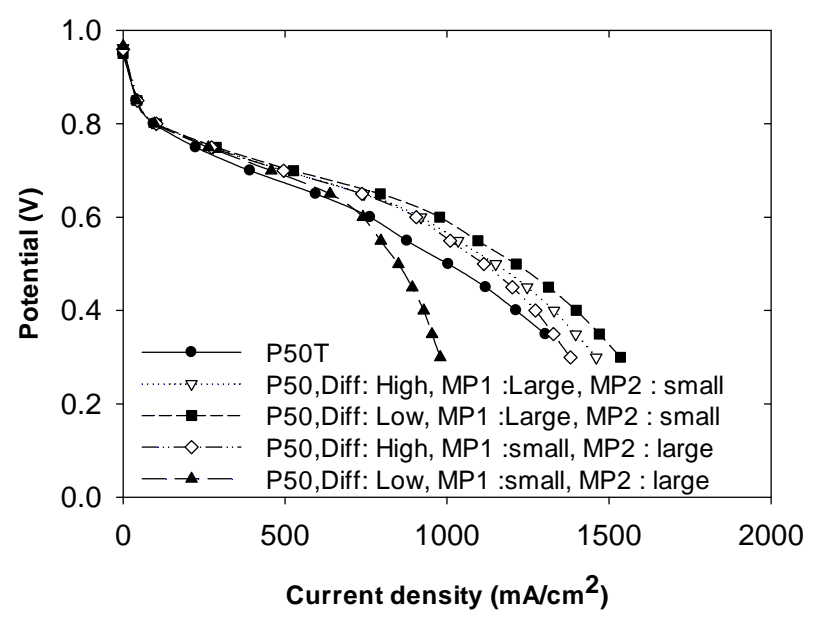

(b) $75 \% / 25 \% \mathrm{RH}$

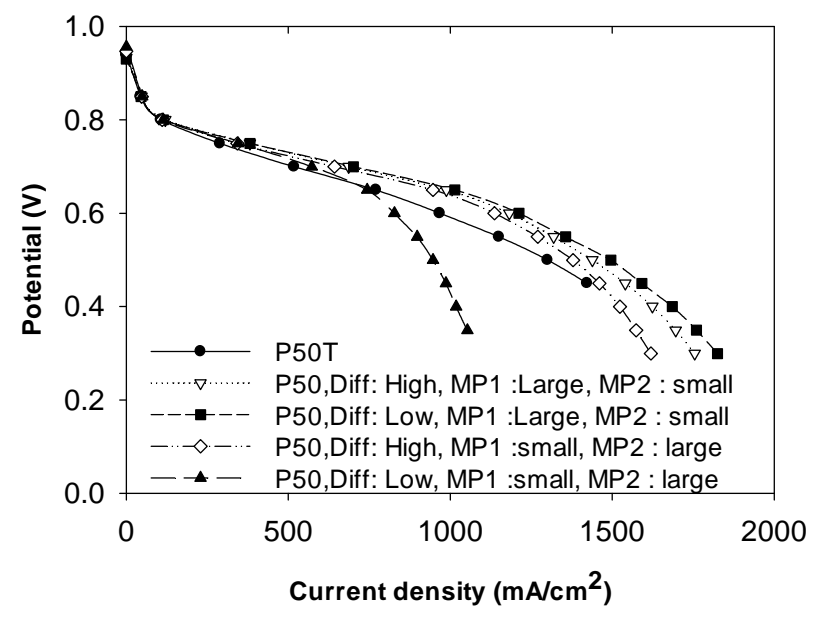

(c) $100 \% / 50 \%$ with $136 \mathrm{kPa}$

Figure 7: 

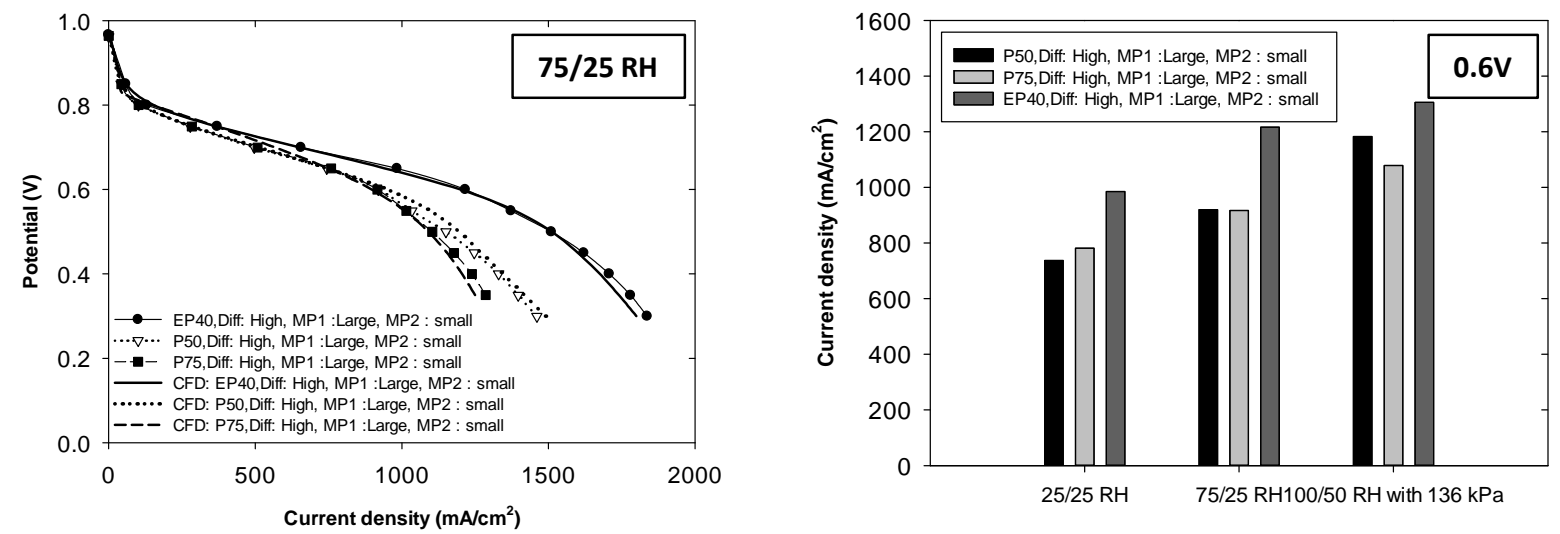

(a) Diffusivity: High MP1: Large MP2: Small
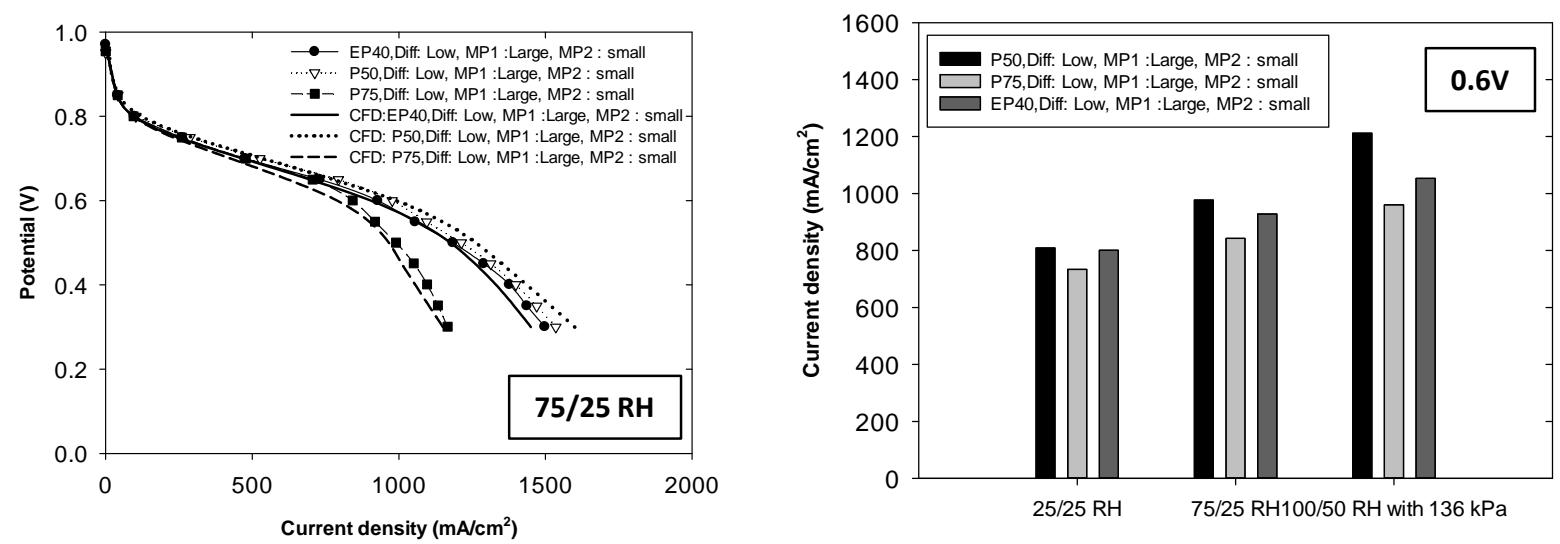

(b) Diffusivity: Low MP1: Large MP2: Small

Figure 8: 

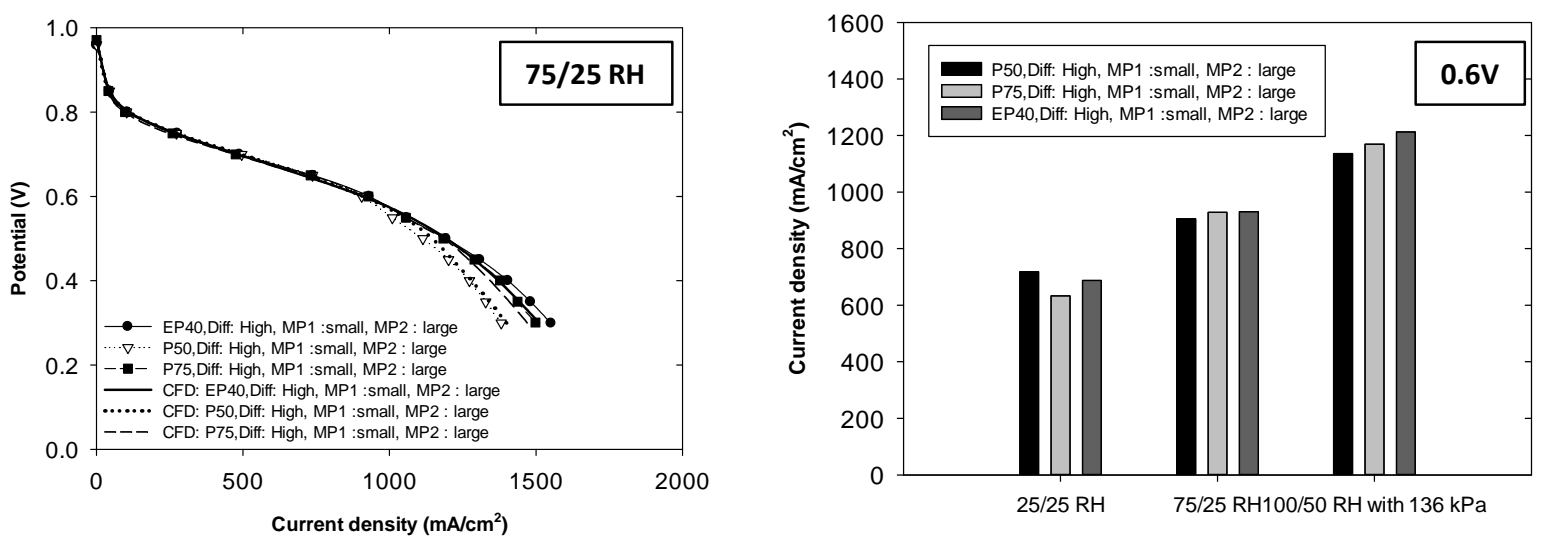

(a) Diffusivity: High MP1: Small MP2: Large
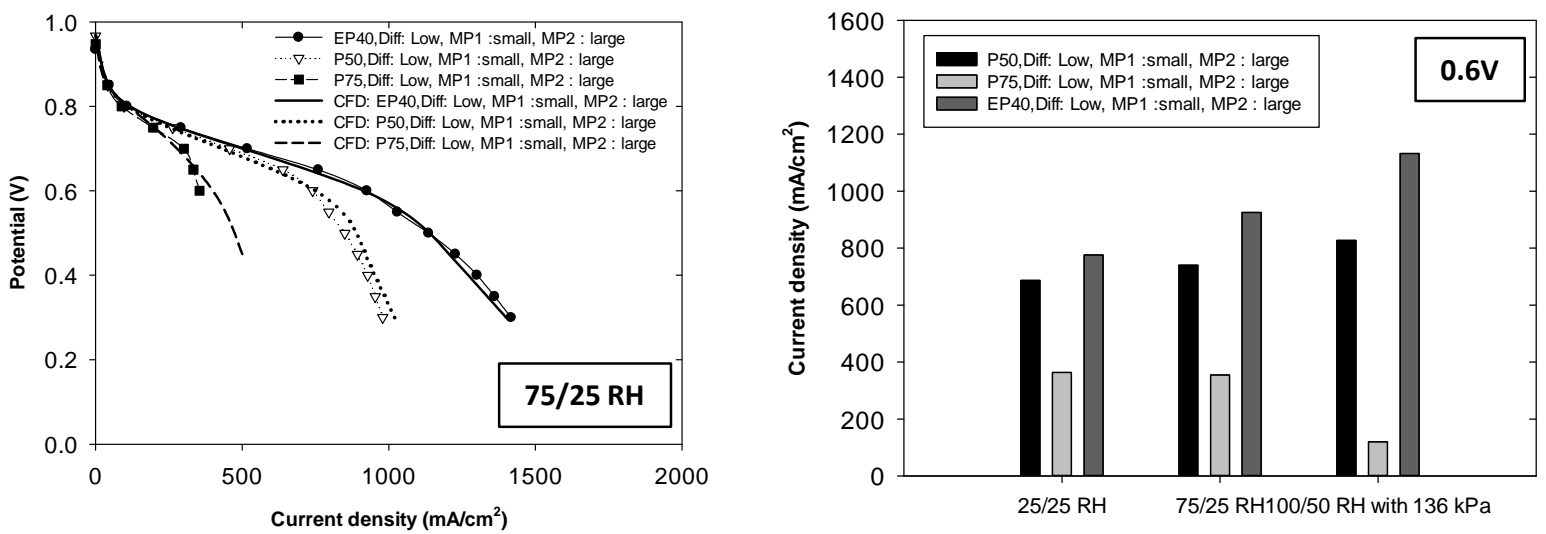

(b) Diffusivity: Low MP1: Small MP2: Large

Figure 9: 


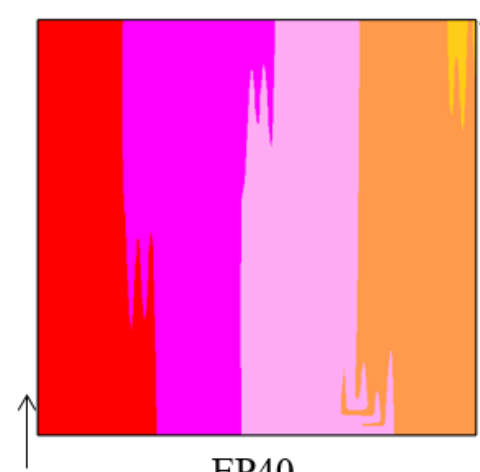

EP40

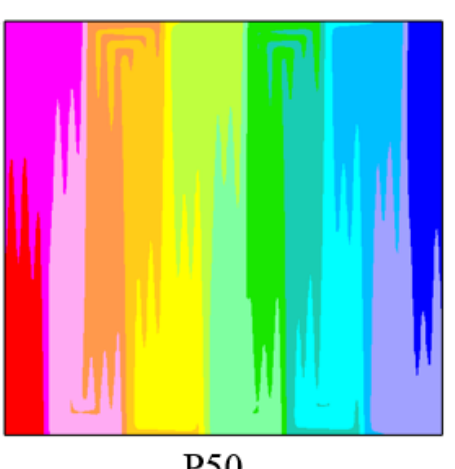

P50

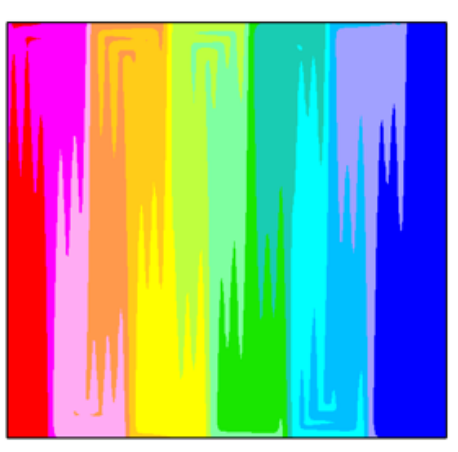

P75

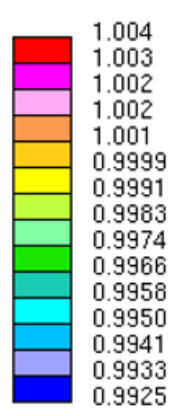

(a) Current density $\left(\mathrm{A} / \mathrm{cm}^{2}\right)$

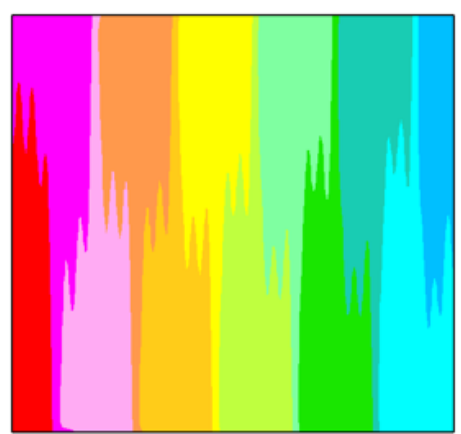

EP40

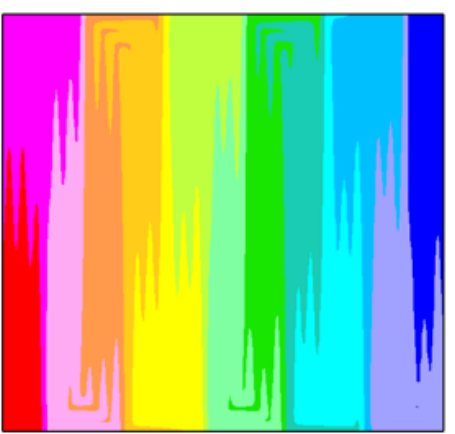

P50

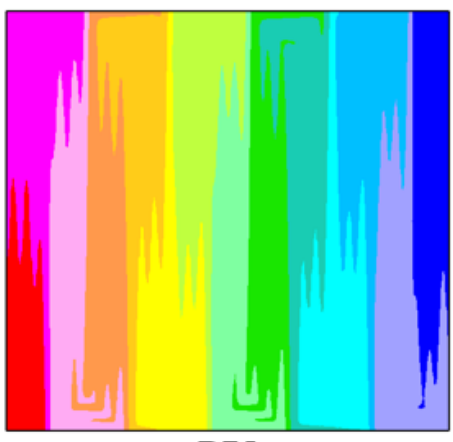

P75

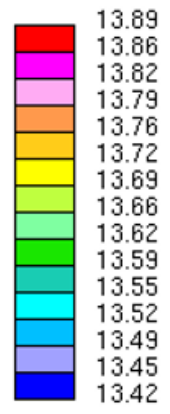

(b) Membrane water content

Figure 10: 


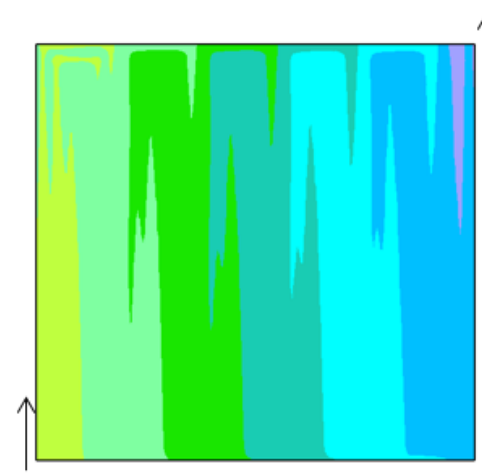

EP40

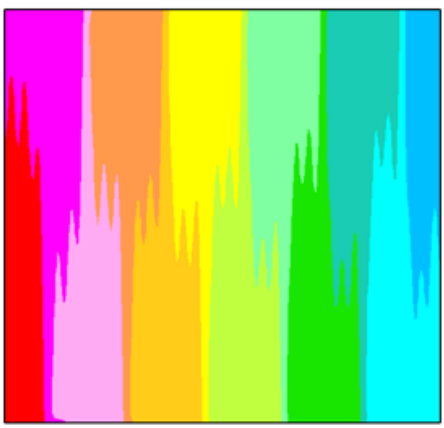

EP40

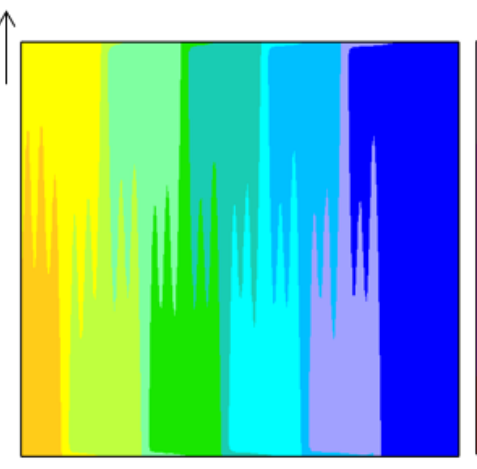

P50

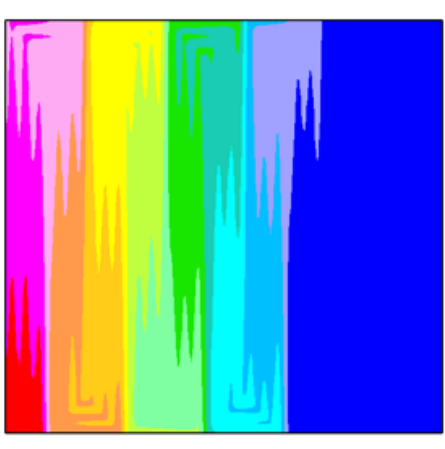

P75

(a) Current density $\left(\mathrm{A} / \mathrm{cm}^{2}\right)$

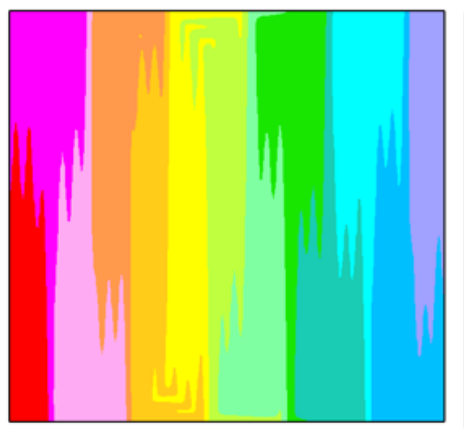

P50

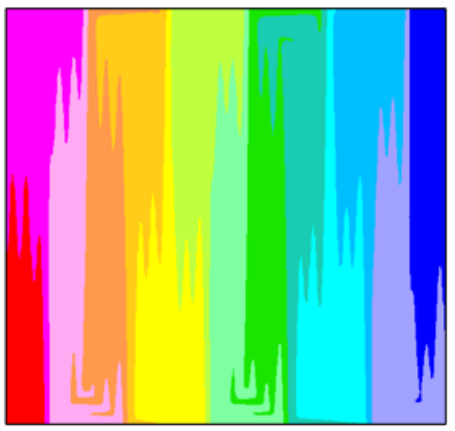

P75

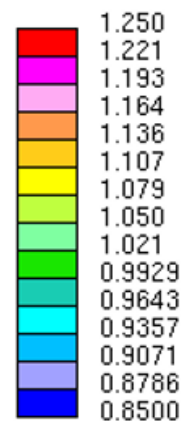

(b) Membrane water content

Figure 11: 
Table 1: Custom GDLs compared with commercial standard

\begin{tabular}{cccccc}
\hline Substrate & Diffusivity & MP1 & MP2 & MacMullin No. & Thickness $(\mu \mathrm{m})$ \\
\hline P50T & & & & 3.09 & 150 \\
P50 & Low & Large & Small & 2.63 & 200 \\
P50 & High & Large & Small & 2.18 & 180 \\
P50 & Low & Small & Large & 4.04 & 200 \\
P50 & High & Small & Large & 2.73 & 180 \\
& & & & & \\
P75T & & & & 4.43 & 240 \\
P75 & Low & Large & Small & 2.14 & 280 \\
P75 & High & Large & Small & 1.92 & 260 \\
P75 & Low & Small & Large & 11.11 & 280 \\
P75 & High & Small & Large & 2.63 & 260 \\
& & & & & \\
EP40T & & & & 3.70 & 190 \\
EP40 & Low & Large & Small & 5.18 & 240 \\
EP40 & High & Large & Small & 2.34 & 220 \\
EP40 & Low & Small & Large & 3.18 & 240 \\
EP40 & High & Small & Large & 2.62 & 220 \\
\hline & & & & &
\end{tabular}


Table 2: Experimental conditions

\begin{tabular}{|c|c|c|c|c|c|}
\hline \multirow{2}{*}{$\begin{array}{l}\mathrm{T}_{\text {cell }} \\
\left({ }^{\circ} \mathrm{C}\right)\end{array}$} & \multirow{2}{*}{$\begin{array}{c}\text { Anode RH } \\
(\%)\end{array}$} & \multirow{2}{*}{$\begin{array}{c}\text { Cathode RH } \\
(\%)\end{array}$} & \multicolumn{2}{|c|}{ Stoichiometry } & \multirow{2}{*}{$\begin{array}{c}\text { Back pressure } \\
(\mathrm{kPa})\end{array}$} \\
\hline & & & Anode & Cathode & \\
\hline \multirow{3}{*}{80} & 25 & 25 & & & 0 \\
\hline & 75 & 25 & 1.5 & 2.0 & 0 \\
\hline & 100 & 50 & & & 136 \\
\hline
\end{tabular}


Table 3: Geometry details

\begin{tabular}{ll}
\hline Description & Value \\
\hline Active area & $50 \mathrm{~cm}^{2}$ \\
Channel width & $0.8 \mathrm{~mm}$ \\
Channel height & $0.5 \mathrm{~mm}$ \\
Rib-spacing width & $0.8 \mathrm{~mm}$ \\
MEA thickness & $35 \mu \mathrm{m}$ \\
Gasket & $178 \mu \mathrm{m}$ \\
\hline
\end{tabular}


Table 4: Properties and parameters

\begin{tabular}{|c|c|}
\hline Current Collector & \\
\hline Thermal conductivity $(\mathrm{W} / \mathrm{m}-\mathrm{K})$ & 5.7 \\
\hline Membrane Electrode Assembly & \\
\hline $\begin{array}{c}\text { Thickness }(\mu \mathrm{m}) \\
\text { (including } 12.5 \mu \mathrm{m} \text { thickness of catalyst layer) }\end{array}$ & 50 \\
\hline Thermal conductivity $(\mathrm{W} / \mathrm{m}-\mathrm{K})$ & 0.15 \\
\hline Dry membrane density $\left(\mathrm{g} / \mathrm{cm}^{3}\right)$ & 2.0 \\
\hline Equivalent weight of dry membrane $(\mathrm{g} / \mathrm{mol})$ & 1100 \\
\hline Cathode exchange current density $\left(\mathrm{A} / \mathrm{cm}^{2}\right)$ & 0.05 \\
\hline Cathode transfer coefficient & 0.619 \\
\hline Anode exchange current density $\left(\mathrm{A} / \mathrm{cm}^{2}\right)$ & 0.5 \\
\hline Anode transfer coefficient & 2.0 \\
\hline
\end{tabular}

